\title{
Optimization and Fabrication of Color Temperature Tunable White LED Luminaires
}

\author{
Da-il Kang ${ }^{1}$, Kun-yul Kim ${ }^{1}$, Young-moon $\mathrm{Yu}^{1}$, and Hee-lack $\mathrm{Choi}^{2 \dagger}$ \\ ${ }^{1}$ LED-Marine Convergence Technology R\&BD Center, Busan 608-739, Korea \\ ${ }^{2}$ Department of Materials Science \& Engineering, Busan 608-739, Korea
}

(Received December 13, 2013; Revised manuscript February 10, 2014; Accepted March 10, 2014)

\begin{abstract}
In this paper the spectra of correlated color temperature (CCT) tunable white light-emitting diode (LED) luminaires, consisting of commercial red, green, blue, and amber LED chips, were optimized to increase color rendering index (CRI), and a special CRI of R9 for deep red color was obtained. To improve the design's accuracy, measured LED spectra were used instead of mathematically modeled ones. Real CCT tunable LED luminaires with CRIs of 87-90 and R9s of 34-93 were fabricated and demonstrated at CCTs of 3000-6000 K.
\end{abstract}

Keywords: Color temperature, LED, Color rendering index, Special CRI, R9

OCIS codes: (330.0330) Vision, color, and visual optics; (330.1715) Color, rendering and metamerism; (330.1730) Colorimetry

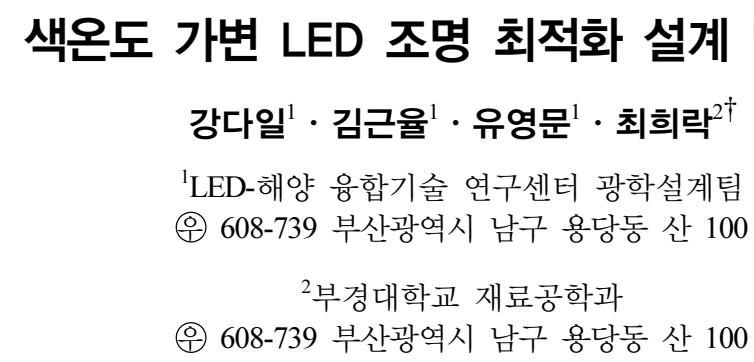

(2013년 12월 13일 받음, 2014년 2월 10일 수정본 받음, 2014년 3월 10일 게재 확정)

본 논문에서는 현재 양산되고 있는 $\operatorname{Red}(621 \mathrm{~nm}), \operatorname{Green}(530 \mathrm{~nm}), \operatorname{Blue}(453 \mathrm{~nm}), \operatorname{Amber}(590 \mathrm{~nm})$ 등 4파장의 LED 조합을 이용 하여 색온도가 가변되는 동안에도 평균연색지수 및 특별연색지수 R9 값이 높게 유지될 수 있도록 조명의 스펙트럼을 최적화하였 다. 최적화 시 설계의 정확도를 높이기 위하여 실제 측정한 LED 스펙트럼을 사용하였고 광선과 기구물 사이의 상호 작용을 고려 한 광선 추적 기법을 활용하여 수행하였다 또한 최적화 결과를 검증하기 위하여 색온도 가변 조명 장치를 직접 제작하였으며 광 특성을 평가한 결과 색온도가 $3000 \mathrm{~K}$ 에서 $6000 \mathrm{~K}$ 까지 변하는 동안 $\mathrm{CRI}$ 및 R9 값이 각각 87 90, 34 93을 나타내었다.

Keywords: 색온도, 발광다이오드, 연색지수, 특별 연색지수, R9

OCIS codes: (330.0330) Vision, color, and visual optics; (330.1715) Color, rendering and metamerism; (330.1730) Colorimetry

\section{I. 서 론}

동일 장소에서 다양한 행위가 이루어지는 현대 건축공간에 서는 분위기와 행위, 작업의 종류 변화에 따라 색온도를 적 합하게 변화시켜 조명의 기능적인 측면과 인간의 감성적인 측면을 동시에 만족시키는 조명환경을 연출할 필요가 있 다. ${ }^{[1]}$ 이러한 요구를 반영하기 위하여 색온도 가변에 대한 연 구가 진행 중에 있으나 조명의 연색성과 같은 인간의 감성에 영향을 미치는 광 특성은 고려하지 않은 연구가 많았다. ${ }^{[2-4]}$
조명의 연색성은 조명이 대상물을 비추었을 때 자연광과 비 교하여 얼마나 대상물의 색을 유사하게 나타내는지를 나타 내는 척도로서 일반적으로 연색지수(CRI)를 사용하여 정량 화 한다. ${ }^{[5]}$ 만약 조명의 색온도가 가변되는 동안 연색지수가 낮아진다면 사물의 색을 제대로 표현하지 못하여 불쾌감을 초래하게 된다. 따라서 색온도 가변 조명을 설계함에 있어 연색성을 반드시 고려할 필요가 있다. 최근 들어 이러한 고 연색성을 유지하는 색온도 가변 조명에 대한 연구가 진행되 고 있다..$^{5-10]}$ 그러나 이러한 연구들의 경우 최적화 시 대부분

\footnotetext{
${ }^{\dagger}$ E-mail: choihr@pknu.ac.kr

Color versions of one or more of the figures in this paper are available online.
} 
수학적 해석 방법을 사용하기 때문에 실제 $\mathrm{LED}$ 의 스펙트럼 을 이용하기 보단 이론적인 수식을 통해 모델링된 LED의 스 펙트럼을 이용하여 LED 조합을 최적화 하고 있다. 이렇게 실제 스펙트럼과 다른 이상적으로 모델링된 LED 스펙트럼 을 이용하여 설계하게 되면 제품을 만들게 되었을 때 색온 도, 연색성 등 광학적 특성이 설계 값과 큰 차이를 보일 것 으로 예상 된다. 또한 최적화에 의해 얻어진 혹은 사용된 $\mathrm{LED}$ 조합들은 시중에서 쉽게 구입하기 어려운 피크파장을 가지는 경우가 많아 실제 제품으로 제작이 힘든 단점이 있 다. 따라서 본 논문에서는 시중에서 쉽게 구할 수 있는 LED 를 고려하였고 이상적인 스펙트럼이 아닌 실제 LED의 스펙 트럼을 측정하여 최적화를 수행하였다. 이때 평균연색지수 (Ra) 뿐만 아니라 진한 적색에 해당하는 특별연색지수 R9도 같이 최적화 하였다. 일반적으로 조명의 연색성을 나타낼 때 $\mathrm{R} 1$ 에서 R8 까지의 연색지수를 평균한 값인 평균연색지수 $(\mathrm{Ra})$ 를 사용하고 있으나 통상적으로 조명의 연색성에 있어서 적색-녹색 간 대비가 중요하고 또한 적색의 연색성이 실제 조명에서 문제를 자주 일으키는 색상이기 때문에 R9 값을 고려할 필요가 있다. ${ }^{[9]}$ 마지막으로 최적화 결과를 검증하기 위하여 실제 조명 기구를 제작하여 그 광학적 특성을 설계값 과 비교 분석 하였다.

\section{II. 최적화 설계}

일반적으로 서로 다른 색을 갖는 다중의 LED 를 사용하여 구 현된 광원의 삼자극치는 아래의 식 (1)에 의하여 구할 수 있다.

$$
\begin{aligned}
& X_{T}=C_{1} X_{1}+C_{2} X_{2}+C_{3} X_{3}+\ldots+C_{N} X_{N} \\
& Y_{T}=C_{1} Y_{1}+C_{2} Y_{2}+C_{3} Y_{3}+\ldots+C_{N} Y_{N} \\
& Z_{T}=C_{1} Z_{1}+C_{2} Z_{2}+C_{3} Z_{3}+\ldots+C_{N} Z_{N}
\end{aligned}
$$

여기서 $\left(\mathrm{X}_{\mathrm{T}}, \mathrm{Y}_{\mathrm{T}}, \mathrm{Z}_{\mathrm{T}}\right)$ 는 색온도 $\mathrm{T}$ 를 갖는 목표광원의 삼자극 치이고 $\left(\mathrm{X}_{\mathrm{N}}, \mathrm{Y}_{\mathrm{N}}, \mathrm{Z}_{\mathrm{N}}\right)$ 은 색혼합을 위해 사용된 LED 각각의 삼자극치이다. 또한, $\mathrm{C}_{\mathrm{N}}$ 은 각 $\mathrm{LED}$ 의 상대 광량비이다. 따 라서 $\mathrm{N}$ 개의 서로 다른 색을 갖는 $\mathrm{LED}$ 의 광량비를 조정함 으로써 목표하는 색온도를 갖는 광원을 만들 수 있다. 그런 데 만일 3 개 이상의 LED 를 조합하는 경우에는 해가 유일하 게 존재하지 않게 된다. 일반적으로 $\mathrm{N}$ 개의 $\mathrm{LED}$ 를 사용하 여 색혼합을 할 경우에는 N-3의 자유도를 갖게 된다. ${ }^{[11]}$ 본 논문에서는 4 개의 LED 를 사용하기 때문에 앞서 언급한 이 유로, 특정 색온도를 만족시키는 RGBA LED 의 조합 수가 다수 존재하게 된다. 따라서 색온도가 가변되는 동안에도 높 은 연색성을 유지하는 스펙트럼을 찾기 위해서는 최적화 과 정이 필요하다. 이와 같은 최적화를 수행하기 위해 상용 수 학 해석 프로그램이나 기 제안된 최적화 알고리즘을 적용한 사례들이 있었다. ${ }^{[8,11]}$ 그러나 이러한 최적화 방법들은 단순 화된 수학적 방법으로, 조명 기구 내에서 일어나는 기구물과 광선 사이의 복잡한 상호 작용 등을 고려하지 않아 실제 제
작 시 설계값과 차이를 나타낼 가능성이 크다. 따라서 본 논 문에서는 이러한 상호 작용 등을 감안하기 위하여 광학 설계 프로그램인 Light Tools(Ver 8.0)를 사용하여 광선추적에 기 반을 둔 최적화를 수행 하였다. 최적화를 진행하기 위해서는 먼저 단일 $\mathrm{LED}$ 에 대한 스펙트럼이 필요하다. 기존에는 단 일 LED 의 피크파장과 반치폭을 변수로 하는 아래의 식 (2) 를 이용하여 좌우대칭인 스펙트럼을 모델링하는 방법이 사 용되었다. ${ }^{[9]}$

$$
\begin{aligned}
& S\left(\lambda, \lambda_{p}, \Delta \lambda, A\right)=A^{*} \frac{g\left(\lambda, \lambda_{p}, \Delta \lambda\right)+2^{*} g^{5}\left(\lambda, \lambda_{p}, \Delta \lambda\right)}{3}, \\
& \text { where } g\left(\lambda, \lambda_{p}, \Delta \lambda\right)=\exp \left[-\left(\frac{\lambda-\lambda_{p}}{\Delta \lambda}\right)^{2}\right] .
\end{aligned}
$$

- $\lambda$ : 파장, $\cdot \lambda \mathrm{p}$ : 피크 파장, $\cdot \Delta \lambda_{0.5}$ : 반치폭, $\cdot \mathrm{A}$ : 진폭

하지만 그림 1에서 보이는 것처럼 식 (2)로 모델링한 스펙 트럼의 경우 피크파장을 기준으로 좌우 대칭인데 비해 실제는 비대칭이라 스펙트럼이 다소 차이가 있는 것을 알 수 있다.

이렇게 실제와는 다른 이상적인 개별 스펙트럼을 이용하여 합성 스펙트럼을 설계한 경우에는 합성 스펙트럼의 색온도 및 연색지수가 예상한 값과 상이한 결과를 초래할 수 있다. 그림 2는 모델링 방법에 의해 생성된 RGBA 스펙트럼을 이 용한 합성 스펙트럼과 동일한 광량비를 만든 후 실제 측정한 스펙트럼을 비교한 결과이다. 동일한 광량비를 적용하였지만

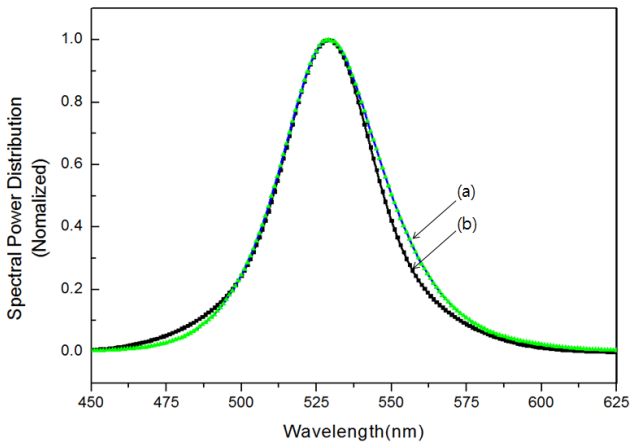

FIG. 1. Measured spectrum (a) and theoretical spectrum (b) of green LED.

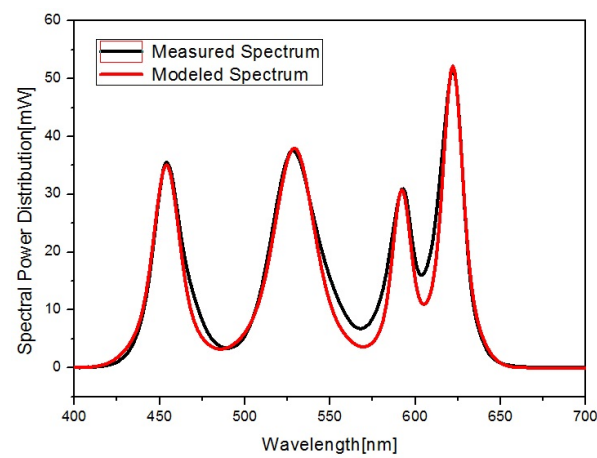

FIG. 2. Modeled spectrum and the measured spectrum. 
모델링한 스펙트럼을 사용한 경우 색온도, 평균연색지수 $(\mathrm{Ra}), \mathrm{R} 9$ 값이 각각 $4794 \mathrm{~K}, 82.4,87.2$ 이었으며 측정한 스 펙트럼의 경우 색온도, 평균연색지수 $(\mathrm{Ra}), \mathrm{R} 9$ 값이 각각 $4525 \mathrm{~K}, 89.7,72.5$ 로 설계값과 실제 측정값이 차이가 남을 확인할 수 있다.

따라서 본 논문에서는 시중에서 쉽게 구매 할 수 있는 $\mathrm{RGBA} \mathrm{LED}$ 를 사용하여 각각의 스펙트럼을 측정하고 이를 바탕으로 색온도가 가변되는 동안에도 높은 평균연색지수 $(\mathrm{Ra})$ 와 R9 값이 유지되도록 각각의 LED 광량비를 최적화 하였다. RGBA LED는 Cree와 Philips Lumileds 사의 제품을 사용하였다(Red : XPE RDO-L1-0000-00A01, Green : LXMLPM01-0090, Blue : XPE ROY-L1-0000-00903, Amber : LXMLPL01-0040).

그림 3은 Red, Green, Blue, Amber LED 를 실제로 적분구 를 사용하여 측정한 스펙트럼과 그때의 각각의 LED 의 피크 파장과 반치폭을 나타내고 있다. 그림에서 볼 수 있듯이 스 펙트럼은 피크파장을 기준으로 다소 비대칭적인 모양을 가 졌다. Red, Green, Blue, Amber LED 의 피크 파장은 각각 $621,530,453,590 \mathrm{~nm}$ 이며 이때 반치폭은 각각 $16,32,21$, $15 \mathrm{~nm}$ 를 가졌다.

앞서 언급한 바와 같이 본 연구에서는 설계의 정확도를 높 이기 위하여 기구물과 광선의 상호 작용을 고려한 광선 추적 기법을 사용하기 때문에 실제 제작될 등기구의 크기 및 기구 물의 광학적 특성을 정확히 반영하는 것이 필요하다. 이를

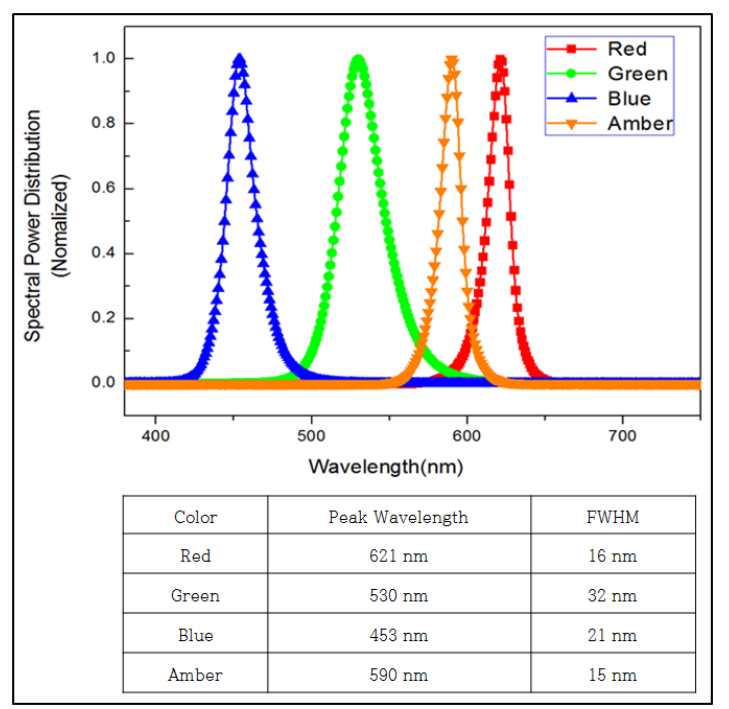

FIG. 3. Spectrum, Peak wavelength, FWHM(full with half maximum of) of each RGBA LED spectrum.
위하여 분광반사율 측정기(Konica Minolta, CM-3700d) 및 산란측정기(J\&C, RT-300S)를 통하여 알루미늄 벽면, 백색 도료를 착색한 $\mathrm{PCB}$ 바닥면, 광확산판 등의 반사-투과율, 산 란 특성을 측정하여 설계에 반영하였다. 그림 4는 모델링한 등기구의 모식도를 나타낸다. 벽면은 반지름 $67 \mathrm{~mm}$, 깊이는 $40 \mathrm{~mm}$ 인 알루미늄 재질의 원형 실린더 모양으로 표면 특성 은 측정 결과를 반영하여 Gaussian 산란(확산각: $\left.1^{\circ}\right)$, 반사율 $85 \%$, 흡수율 $15 \%$ 로 하였고 바닥면은 백색의 PCB 면으로 Lambertian 산란, 반사율 $85 \%$, 흡수율 $15 \%$ 로 하였다. 조명 기구의 상부에는 색혼합 및 눈부심 방지를 위하여 광 확산판 을 두었으며 반지름은 $65 \mathrm{~mm}$, 두께는 $2 \mathrm{~mm}$, Taper 는 1, 벽 면 산란 특성은 Lambertian 으로 하였다. 검출기는 발광면 바 로 $3 \mathrm{~mm}$ 위에 설치하였다. 최적화를 위한 변수로 RGBA LED 의 광 세기(Radiometric Power)를 지정하였고 색도거리(Chromaticity Distance)를 0.005 이하가 되도록 제한 조건을 설정하였다.

표 1은 본 논문에서 사용된 4 chip LED 조합(621-530$453-590 \mathrm{~nm}$ )을 이용하여 $3000 \mathrm{~K}$ 에서 $6000 \mathrm{~K}$ 까지 $500 \mathrm{~K}$ 단위로 총 7 가지 색온도의 최적화 전후의 광특성을 나타내 고 있다. 최적화 전의 스펙트럼은 식(1)를 이용하여 색온도 를 만족하는 임의의 조합을 선정한 것이다. 표 1 를 통해 알 수 있는 것처럼 동일한 $\mathrm{LED}$ 를 사용하여 동일한 색온도를 가지는 백색광을 만들었지만 각각의 RGBA LED 의 세기를 최적화 하지 않을 경우 광 특성의 차이가 크게 나타남을 보 여준다.

최적화의 효과를 좀 더 구체적으로 보이기 위하여 색온도 $4500 \mathrm{~K}$ 에서 임의로 선정한 조합과 최적화 과정을 통하여 산출한 조합의 스펙트럼과 그 광 특성을 비교하였다. 그림 5 는 동일한 $4500 \mathrm{~K}$ 를 갖는 스펙트럼을 나타내고 있다. 최적 화 전의 스펙트럼 그림 5(a)의 경우 평균연색지수는 69 , 특별 연색지수 R9은 -152였으며 최적화 이후의 스펙트럼 그림

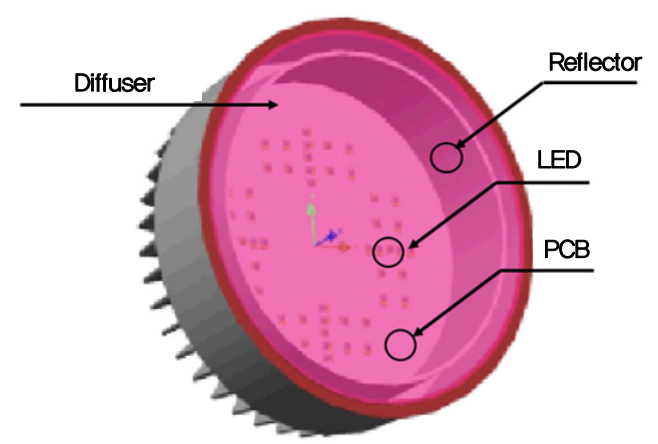

FIG. 4. Schematic diagram of down light.

TABLE 1. Comparison of the optical properties before and after simulation optimization

\begin{tabular}{|c|c|c|c|c|c|c|c|c|c|}
\hline \multicolumn{2}{|c|}{ Optimization } & $3000 \mathrm{~K}$ & $3500 \mathrm{~K}$ & $4000 \mathrm{~K}$ & $4500 \mathrm{~K}$ & $5000 \mathrm{~K}$ & $5500 \mathrm{~K}$ & $6000 \mathrm{~K}$ & average \\
\hline \multirow{2}{*}{ Before } & CRI (Ra) & 82 & 76 & 72 & 69 & 74 & 73 & 70 & 74 \\
\hline & R9 & -51 & -86 & -120 & -152 & -121 & -131 & -158 & -117 \\
\hline \multirow{2}{*}{ After } & CRI (Ra) & 89 & 90 & 90 & 90 & 91 & 90 & 90 & 90 \\
\hline & R9 & 32 & 48 & 56 & 65 & 62 & 66 & 67 & 57 \\
\hline
\end{tabular}




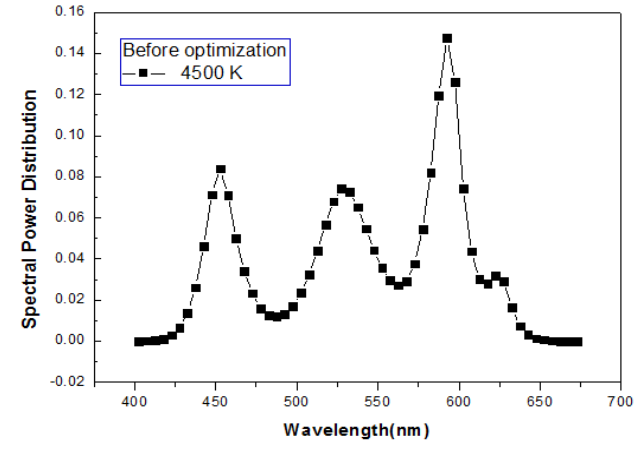

(a)

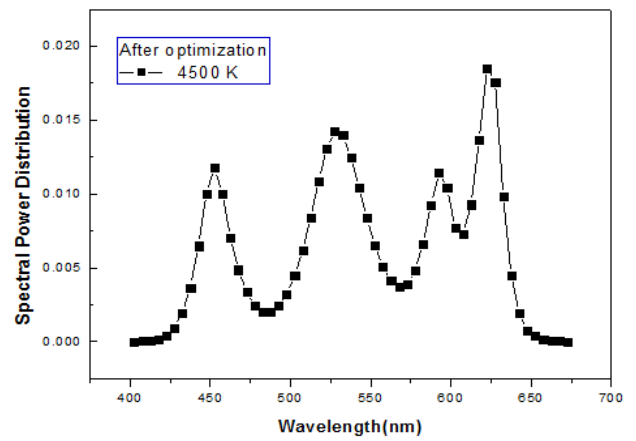

(b)

FIG. 5. Spectrum before optimization (a), spectrum after optimization (b) at $4500 \mathrm{~K}$.

TABLE 2. The ratio of light intensity about each RGBA LEDs at each color temperature

\begin{tabular}{c|c|c|c|c|c|c|c|c}
\hline \hline & Number & $3000 \mathrm{~K}$ & $3500 \mathrm{~K}$ & $4000 \mathrm{~K}$ & $4500 \mathrm{~K}$ & $5000 \mathrm{~K}$ & $5500 \mathrm{~K}$ & $6000 \mathrm{~K}$ \\
\hline $\mathrm{R}$ & 12 & 1.000 & 0.940 & 0.818 & 0.747 & 0.693 & 0.636 & 0.598 \\
\hline $\mathrm{G}$ & 16 & 0.895 & 1.000 & 1.000 & 1.000 & 1.000 & 1.000 & 1.000 \\
\hline $\mathrm{B}$ & 8 & 0.266 & 0.405 & 0.496 & 0.602 & 0.732 & 0.767 & 0.835 \\
\hline $\mathrm{A}$ & 16 & 0.457 & 0.428 & 0.378 & 0.350 & 0.374 & 0.338 & 0.334 \\
\hline
\end{tabular}

5(b)는 평균연색지수 90, 특별연색지수 R9 65를 나타내었다.

본 연구에서 사용한 광학 시뮬레이션 프로그램은 최적화시 Monte-Carlo 방법에 의하여 국소적인 최적값을 찾기 때문에 시뮬레이션의 초기 조건에 의해 최적값이 달라질 수 있다. 따라서 최적화 시 초기 조건을 변경하면서 가능한 높은 연색 지수를 얻도록 노력하였으나 표 1에서 산출한 연색지수가 이론적으로 얻을 수 있는 가장 높은 값이라고 말할 수는 없 다. 하지만 이상적인 파장 대역을 갖는 LED 가 아닌 상용화 된 $\mathrm{LED}$ 의 조합을 이용한 것을 감안하면 $3000 \mathrm{~K}$ 에서 6000 $\mathrm{K}$ 까지 색온도가 가변되는 동안 평균연색지수가 89 91 값을 갖는 것은 비교적 높은 수준이라 할 수 있다.

표 2는 최적화가 완료된 후 색온도별 각각 $\mathrm{LED}$ 의 상대 광량비를 나타내고 있다.

\section{III. 제작 및 측정결과}

최적화의 결과를 실험적으로 검증하기 위하여 LED 등기 구를 실제 제작하였다. 다중의 컬러 $\mathrm{LED}$ 를 혼합하여 백색 조명을 구현하는 경우 조명이 비추는 면의 색혼합도 중요하 지만 조명 발광면에서의 색혼합도 중요하다. 왜냐하면 사람 의 눈으로 조명을 바라봤을 때 백색이 아닌 얼룩한 컬러 색 이 보일 경우 미적으로 거부감을 느낄 수 있기 때문이다. 따 라서 LED 등기구 제작 시 광 확산판 표면의 색도가 균일할 수 있도록 RGBA LED 배치를 최적화 하였다.

그림 6은 세 가지 LED 배치에 따른 광 확산판 표면의 색 도를 나타낸 그림이다. LED 의 배치는 그림 6(a)의 경우 LED 들이 벽면으로 배치되었을 때 시뮬레이션 상으로 나타 난 그림으로서 색 혼합이 제대로 되지 않아 노란 십자가 모
양이 나타남을 알 수 있다. 그림 6(c)의 경우 Blue LED 를 안쪽으로 모을 경우에 가운데 푸른 원이 생겼다. 이를 보완 하기 위해 RGBA LED 를 안쪽으로 배치하여 그림 6(b)와 같 은 비교적 균일한 색을 나타내는 배치를 찾았다.

그림 7은 실제 제작한 $\mathrm{LED}$ 등기구를 나타내고 있다. $\mathrm{RGBA} \mathrm{LED}$ 의 광 효율과 각각의 색온도에서 필요한 광량을 고려하여 LED의 개수는 Red LED 12개, Green LED 16개, Blue LED 8개, Amber LED 16개로 하였다. 그림 7(a)는 $\mathrm{PCB}$ module를 등기구 내부에 장착한 후 광 확산판 없이 점 등한 사진이고 그림 $7(\mathrm{~b})$ 는 광 확산판을 장착한 후 점등한 사진으로서 발광면의 색혼합이 잘 이루어 진 것을 확인할 수 있다.

표 3은 최적화를 통하여 구한 광량비를 맞추기 위해 필요 한 색온도별 각각의 LED 에 인가되어지는 전류의 세기를 나 타내고 있다(단위 : $\mathrm{mA}$ ).

제작을 완료한 색온도 가변 조명을 적분구(OPI-1000)에서 $3000 \sim 6000 \mathrm{~K}$ 까지 $500 \mathrm{~K}$ 단위로 7가지 색온도에 대해서 측 정하였다. 그림 8은 $3000 \mathrm{~K}, 4000 \mathrm{~K}, 5000 \mathrm{~K}, 6000 \mathrm{~K}$ 에서의 $\mathrm{RGBA} \mathrm{LED}$ 에 필요한 전류를 인가하여 적분구를 사용하여 얻어낸 스펙트럼이다.

표 4에서 색온도 가변 조명의 광특성 설계값 과 측정값을 비교하였다. 먼저 색온도의 경우 설계값과 비교하여 약간의 차이를 나타내는 것으로 보이지만 한국산업규격(KS) LED 등기구의 색온도 범위가 $3000 \mathrm{~K}$ 에서 $\pm 175 \mathrm{~K}, 6500 \mathrm{~K}$ 에서 $\pm 510 \mathrm{~K}$ 인 점을 감안하면 미미한 수준이라 할 수 있다. 각 색온도에서의 평균연색지수 $(\mathrm{Ra})$ 와 특별연색지수 R9의 값도 설계값과 거의 일치함을 확인할 수 있었으며 결론적으로 색 온도가 가변되는 동안 평균연색지수 $(\mathrm{Ra})$ 및 R9의 평균값이 


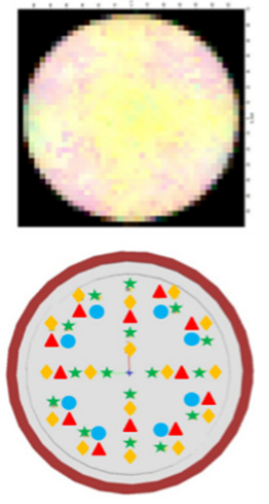

(a)
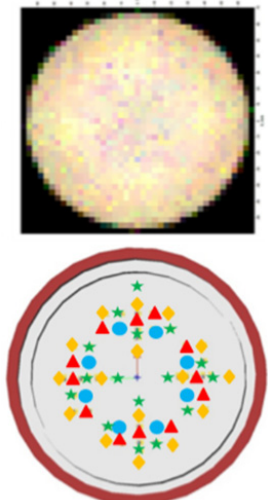

$\Delta$ : Red, $\star$ : Green, $\bullet:$ Blue, $\diamond:$ Amber

(b)
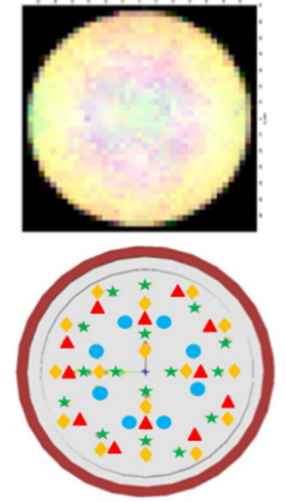

(c)

FIG. 6. The color of diffuser plate according to three kinds of LED arrangement.

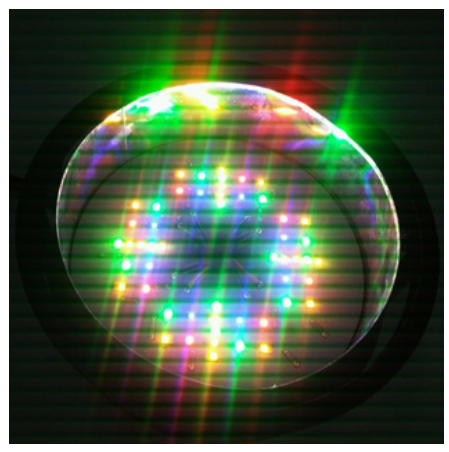

(a)

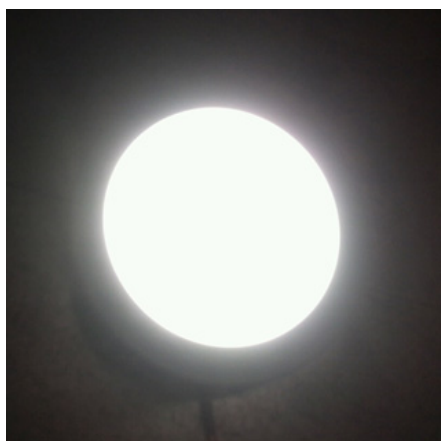

(b)

FIG. 7. (a) Without the diffuser plate, (b) with the diffuser plate.

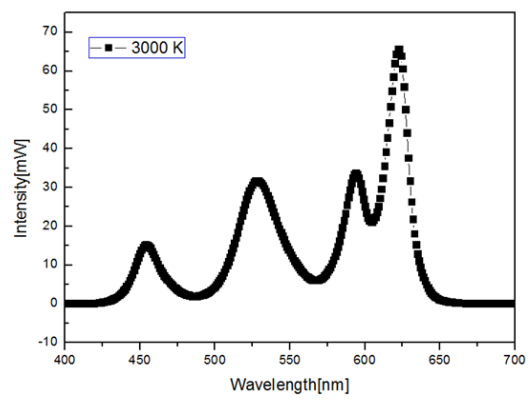

(a)

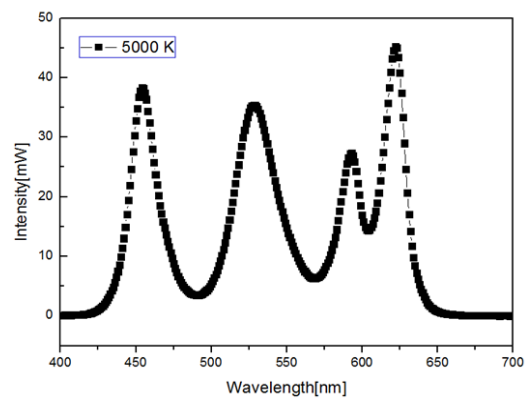

(c)

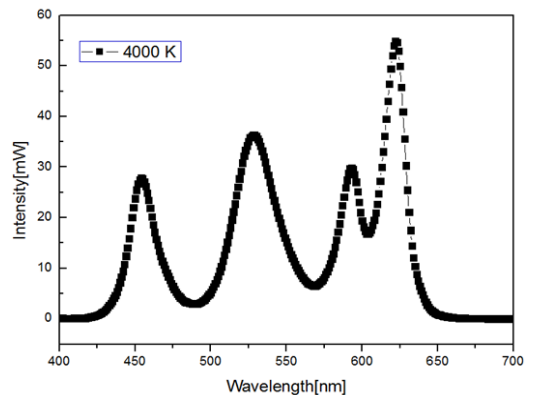

(b)

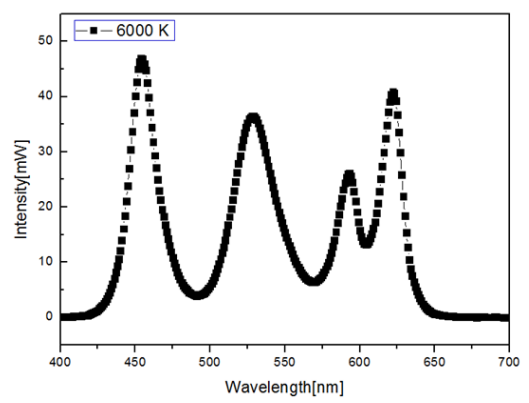

(d)

FIG. 8. Spectrum of LED luminaire at (a) $3000 \mathrm{~K}$, (b) $4000 \mathrm{~K}$, (c) $5000 \mathrm{~K}$, (d) $6000 \mathrm{~K}$. 
TABLE 3. Initial current's amount of each LEDs from $3000 \mathrm{~K}$ to $6000 \mathrm{~K}$

\begin{tabular}{c|c|c|c|c|c|c|c|c}
\hline \hline & Number (ea) & $3000 \mathrm{~K}$ & $3500 \mathrm{~K}$ & $4000 \mathrm{~K}$ & $4500 \mathrm{~K}$ & $5000 \mathrm{~K}$ & $5500 \mathrm{~K}$ & $6000 \mathrm{~K}$ \\
\hline $\mathrm{R}$ & 12 & 279 & 253 & 233 & 218 & 207 & 192 & 190 \\
\hline $\mathrm{G}$ & 16 & 636 & 688 & 712 & 736 & 791 & 765 & 778 \\
\hline $\mathrm{B}$ & 8 & 41 & 75 & 114 & 141 & 156 & 185 & 211 \\
\hline $\mathrm{A}$ & 16 & 690 & 607 & 587 & 522 & 474 & 502 & 495 \\
\hline
\end{tabular}

TABLE 4. The optical properties data of designed and fabricated LED luminaire

\begin{tabular}{|c|c|c|c|c|c|c|c|c|}
\hline $\begin{array}{l}\text { Color temperature }(\mathrm{K}) \text { of designed } \\
\text { LED luminaire }\end{array}$ & 3000 & 3500 & 4000 & 4500 & 5000 & 5500 & 6000 & average \\
\hline $\mathrm{Ra}$ & 89 & 90 & 90 & 90 & 91 & 90 & 90 & 90 \\
\hline R9 & 32 & 48 & 56 & 65 & 62 & 66 & 67 & 57 \\
\hline LER $(\operatorname{lm} / \mathrm{W})$ & 393 & 382 & 373 & 361 & 349 & 344 & 338 & 363 \\
\hline $\begin{array}{c}\text { Color temperature }(\mathrm{K}) \text { of fabricated } \\
\text { LED luminaire }\end{array}$ & 2934 & 3447 & 3926 & 4449 & 4975 & 5579 & 6040 & average \\
\hline $\mathrm{Ra}$ & 87 & 89 & 89 & 89 & 90 & 89 & 88 & 89 \\
\hline R9 & 34 & 52 & 63 & 76 & 82 & 93 & 90 & 70 \\
\hline LER $(\operatorname{lm} / \mathrm{W})$ & 401 & 388 & 371 & 360 & 356 & 341 & 331 & 364 \\
\hline
\end{tabular}

각각 89,70 에 달하는 조명 기구를 구현하였다.

\section{IV. 결 론}

RGBA 4-chip LED 조합을 사용하여 색온도가 가변되는 동안에도 높은 연색성을 유지하는 등기구를 설계 제작하였 다. 최적화 설계는 실제 제작이 가능하도록 상용화되어 있는 $\mathrm{LED}$ 를 이용하여 수행하였으며 또한 설계의 정확도를 높이 기 위하여 실제 측정한 $\mathrm{LED}$ 스펙트럼을 사용하였고 광선 추 적 기법을 적용하여 광선과 기구물 사이의 상호 작용이 최적 화될 수 있도록 고려하였다. 최종적으로 제작된 조명기기는 색온도가 $3000 \mathrm{~K} \sim 6000 \mathrm{~K}$ 로 가변되는 동안 평균연색지수 (Ra) 87 90, R9은 34 93을 나타내었다.

\section{감사의 글}

본 논문은 부경대학교 자율창의 연구비(2013년)에 의하여 연구되었음.

\section{References}

1. I.-T. Kim, J.-Y. Kim, and A.-S. Choi, "A basic study of control algorithm for development of the adjustable CCT LED lighting system in architectural spaces," in Proc. The Korean Institute of Illuminating and Electrical Installation Engineers 2011 Spring Conference (2011), pp. 73-74.

2. J.-S. Lee, W.-D. Kim, and S.-Y. Kim, "Sensibility evaluation of LED lighting and fluorescent lamp based on color," Proc. Architectural Institute of Korea 25, 04 (2009).
3. Y. J. Park, J. H. Choi, and M. G. Jang, "Optimization of light source combination through the illuminance and color temperature simulation of circadian lighting apparatus," Int. J. Contents 9, 248-254 (2009).

4. J.-S. Yang, "A study on the autumn LED emotional lighting color through the comparative analysis of the daylighting and LED lighting color," Journal of the Korea Institute of Illuminating and Electrical Installation Engineers 25, 1-13 (2011).

5. Y. Ohno, "Color rendering and luminous efficacy of white LED spectra," Proc. SPIE 5530, Fourth International Conference on Solid State Lighting, 88 (October, 2004).

6. G. He and L. Zheng, "Color temperature tunable whitelight-emitting diode clusters with high color rendering index," Appl. Opt. 49, 4670-4676 (2010).

7. Z. Lei, G. Xia, L. Ting, G. Xiaoling, L. Q. Ming, and S. Guangdi, "Color rendering and luminous efficacy of trichromatic and tetrachromatic LED-based white LEDs," Microelectronics Journal 38, 1-6 (2007).

8. P. Zhong, G. He, and M. Zhang, "Spectral optimization of the color temperature tunable white light-emitting diode (LED) cluster consisting of direct-emission blue and red LEDs and a diphosphor conversion LED," Opt. Express 20, A684-A693 (2012).

9. Y. Ohno, "Spectral design considerations for white LED color rendering," Opt. Eng. 44, 111302 (2005).

10. G. He and L. Zheng, "White-light LED clusters with high color rendering," Opt. Lett. 35, 2955-2957 (2010).

11. H. Ries, I. Leike, and J. Muschaweck, "Optimized additive mixing of colored light-emitting diode sources," Opt. Eng. 43, 1531-1536 (2004). 